\title{
Determining the Impact of Ethnicity on the Accuracy of Measurements of Oxygen Saturations. A Retrospective Cohort Study
}

\#M.N. Bangash ${ }^{1,2}$, \# J. Hodson ${ }^{3,4}$, F. Evsion ${ }^{3,4}$, J.M.Patel ${ }^{1,2}$, A.McD. Johnston ${ }^{1,2,5}$, S Gallier $^{3,4}$ E Sapey $^{1,4,5}{ }^{*}$ D. Parekh ${ }^{1,2}$

1. \#Dr Mansoor N Bangash, Consultant Anaesthesia and Critical Care Medicine. Mansoor.Bangash@uhb.nhs.uk, ORCiD ID: 0000-0001-5039-5184.

2. \#ames Hodson, Statistician, James.Hodson@uhb.nhs.uk. ORCiD ID: 0000-0003-3487-0090

3. Felicity Evison, Principal Research Informatician. Felicity.Evison@UHB.nhs.uk. ORCiD ID: 0000-0002-9378-7548

4. Dr Jaimin M Patel, Consultant Anaesthesia and Critical Care Medicine. Jaimin.Patel@uhb.nhs.uk. ORCiD ID: 0000-0003-4120-3923

5. Lt Col Andrew McD Johnston, Consultant Critical Care and Respiratory Medicine, Andy.johnston@uhb.nhs.uk. ORCiD ID: 0000-0002-0220-0589

6. Suzy Gallier. Director of PIONEER, Head of Research Informatics, Suzy.gallier@uhb.nhs.uk ORCiD ID: 0000-0003-1026-4125

7. Professor Elizabeth Sapey, Professor of Acute and Respiratory Medicine, Director of PIONEER E.Sapey@bham.ac.uk. ORCiD ID: 0000-0003-3454-5482

8. *Dr Dhruv Parekh. Senior Clinical Lecturer Acute and Critical Care. D.Parekh@bham.ac.uk ORCiD ID: 0000-0002-1508-8362

Corresponding address: Institute of Inflammation and Ageing, University of Birmingham, 1st Floor, New Queen Elizabeth Hospital, Mindelsohn Way, Birmingham, B15 2WB, UK *Corresponding and senior author.

${ }^{\#}$ Contributed equally

Affiliations

1. Birmingham Acute Care Research Group, Institute of Inflammation and Ageing, University of Birmingham, UK

2. Department of Critical Care, University Hospitals Birmingham NHS Foundation Trust, Birmingham, UK.

3. Department of Health Informatics, University Hospitals Birmingham NHS Foundation Trust, Birmingham, UK.

4. PIONEER: Health Data Research UK (HDRUK) Health Data Research Hub for Acute Care

5. Department of Acute Medicine Acute Medicine, University Hospitals Birmingham NHS Foundation Trust, Edgbaston, Birmingham, B15 2GW, UK

\section{Running title - Discrepancies in oxygen saturations}

Key words: inequalities, ethnicity, oxygen saturations 


\begin{abstract}
Background

Pulse oximeters are routinely used in community and hospital settings worldwide as a rapid, noninvasive, and readily available bedside tool to approximate blood oxygenation. Potential racial biases in $\mathrm{SpO} 2$ measurements may influence the accuracy of pulse oximetry readings and impact clinical decision making. We aimed to assess whether the accuracy of oxygen saturation measured by peripheral pulse oximetry ( $\mathrm{SpO} 2$ ), relative to arterial blood gas ( $\mathrm{SaO} 2)$, varies by ethnicity.

\section{Methods}

In this large retrospective observational cohort study covering four NHS Hospitals serving a large urban population in Birmingham, consecutive patients admitted to hospital requiring oxygen therapy were identified by electronic patient records. For each spell, the first available pair of $\mathrm{SpO} 2$ and $\mathrm{SaO} 2$ measurements taken within an interval of less than 20 minutes were identified and included in the analysis. The differences between $\mathrm{SpO} 2$ and $\mathrm{SaO} 2$ measurements, were compared across selfidentified groups of ethnicities. These differences were subsequently adjusted for age, sex, bilirubin, systolic blood pressure, carboxyhaemaglobin saturations and the time interval between $\mathrm{SpO} 2$ and $\mathrm{SaO} 2$ measurements.
\end{abstract}

\title{
Findings
}

Paired 02 saturation measurements from 16818 inpatient spells between 1st January 2017 and 18th February 2021, were analysed. The cohort self-identified as being of White (81.2\%), Asian (11.7\%), Black (4.0\%), or Other (3.2\%) ethnicities. Across the cohort, SpO2 was significantly higher than $\mathrm{SaO} 2$ (median: $98 \%$ vs. 97\%, $p<0.001$ ), with a median difference of 0.5 percentage points (pps). However, the size of this difference varied considerably with the magnitude of $\mathrm{SaO} 2$, with $\mathrm{SpO} 2$ overestimation by a median of $3.8 \mathrm{pp}$ for $\mathrm{SaO} 2$ values $<90 \%$ but underestimating by a median of $0.4 \mathrm{pp}$ for an $\mathrm{SaO} 2$ of $95 \%$. The differences between $\mathrm{SpO} 2$ and $\mathrm{SaO} 2$ were also found to vary significantly by ethnicity, with this difference being $0.8 \mathrm{pp}$ (95\% confidence interval: $0.6-1.0$ ) greater in those of Black vs. White ethnicity. These differences resulted in $6.1 \%$ vs. $8.7 \%$ of White vs. Black patients classified as normoxic on $\mathrm{SpO} 2$ who were hypoxic on the gold standard $\mathrm{SaO} 2$ reading $(p=0.007)$.

\section{Interpretation}

Pulse oximetry tends to overestimate $\mathrm{O} 2$ saturation, and this is more pronounced in patients of Black ethnicity. Prospective studies are urgently warranted to assess the impact of ethnicity on the accuracy of pulse oximetry, to ensure care is optimised for all.

\section{Funding}

This work was supported by PIONEER, the Health Data Research UK (HDR-UK) Health Data Research Hub in acute care. HDR-UK is an initiative funded by the UK Research and Innovation, Department of Health and Social Care (England) and the devolved administrations, and leading medical research charities. 


\section{Introduction}

Ensuring optimal oxygen delivery to tissues is a prime objective of acute/critical medical care. Using arterial blood gas ( $A B G$ ) sampling and co-oximetry analysis to measure arterial blood oxygen saturation ( $\mathrm{SaO} 2$ ) is considered the gold standard means of assessing blood oxygenation. ${ }^{1}$ However, $A B G$ measurement is an invasive and labour-intensive test. Pulse oximeter measured oxygen saturation (SpO2) is a non-invasive approximation of SaO2. First developed in $1974^{2}$, pulse oximeters have been routinely used in both community and hospital settings for the past forty years, and are widely acknowledged to be highly important clinical monitoring devices that improve patient safety. ${ }^{3}$

The measurement of oxygen saturation by pulse oximetry is based upon two principles. The first is that oxyhaemoglobin $(\mathrm{O} 2 \mathrm{Hb})$ and deoxyhaemoglobin $(\mathrm{Hb})$ have different absorption spectra, with $\mathrm{O} 2 \mathrm{Hb}$ absorbing greater amounts of infrared light and lower amounts of red light, compared to $\mathrm{Hb}$. The second is that beat-to-beat variation of tissue blood volume produces a light transmission signal which depends only on the pulse characteristics of arterial blood. Pulse oximeters emit two wavelengths of light, red at $660 \mathrm{~nm}$ and near-Infrared at $940 \mathrm{~nm}$, from a pair of light-emitting diodes located in one side of the probe, which is usually placed on a finger (over the nailbed). The transmission of the two wavelengths of light through the finger is then detected by a photodiode on the opposite arm of the probe, and the relative amount of red and infrared light absorbed are ultimately used to determine the proportion of $\mathrm{Hb}$ bound to oxygen. ${ }^{4}$ Pulse oximetry only detects the oxygen saturation of arterial blood, through subtraction of non-varying, venous (deoxygenated) blood spectra, due to the recognition of fluctuations in absorbed light caused by the cardiac cycle. ${ }^{5}$

The accuracy of pulse oximetry readings is vital. Overestimation of actual $\mathrm{SaO} 2$ might lead to clinically relevant hypoxaemia remaining undetected and untreated. Conversely, underestimation of actual $\mathrm{SaO} 2$ may result in unnecessary oxygen therapy, with the potential risks of hyperoxaemia ${ }^{6}$, oxygen wastage and inappropriate clinical decision making, including severity of illness assessment and safe discharge from hospital. The United States Regulatory body which governs approvals for medical devices, the Food and Drug Administration (FDA), requires the accuracy of pulse oximeters to be tested against $\mathrm{SaO} 2$, with the root-mean-square difference between the $\mathrm{SpO} 2$ and the true $\mathrm{SaO} 2$ being within $\pm 2-3 \%{ }^{7}$ There are known conditions where $\mathrm{SpO} 2$ readings may not accurately reflect the true $\mathrm{SaO} 2$. These include, but are not limited to, methaemoglobinaemia ${ }^{8}$, severe carbon monoxide poisoning ${ }^{9}$, hyperbilirubinaemia ${ }^{5}$, excessive movement, hypotension and hypoperfusion states, severe anaemia, and increased blood glycohaemoglobin. ${ }^{51011}$

A recent study has highlighted potential racial biases in $\mathrm{SpO} 2$ measurements. ${ }^{12}$ In this study, the frequency of occult hypoxemia that was not detected by $\mathrm{SpO} 2$ was almost three times higher in Black patients, compared to White patients. There have been previous, much smaller studies assessing the impact of skin pigmentation on the accuracy of $\mathrm{SpO} 2$ compared to $\mathrm{SaO} 2$, but often with discordant results. ${ }^{13-15}$

Given the widespread use of $\mathrm{SpO} 2$ in clinical decision making worldwide, guidance suggesting narrow therapeutic windows for oxygen therapy ${ }^{16}$, and care pathways placing more emphasis on early discharge, ambulatory and home monitoring for patient management, any systemic differences between $\mathrm{SpO} 2$ and $\mathrm{SaO} 2$ could have major health implications. On the other hand, adjustments to 
measurements on the basis of ethnicity (for example, the estimated glomerular filtration) are now increasingly controversial ${ }^{17} 18$, and there has been considerable interest in revalidating scoring systems to remove references to ethnicity. ${ }^{19}$ As such, any changes to clinical practice or test interpretation driven by ethnicity requires a sound evidence base.

Birmingham, UK is one of the most diverse urban centres in the UK. ${ }^{20}$ The aim of this study was to assess whether $\mathrm{SpO} 2$ accurately predicted $\mathrm{SaO} 2$, measured by $\mathrm{ABG}$, and whether disparities between ethnicities existed.

\section{Methods}

\section{Study design and population}

This data study was supported by PIONEER, a Health Data Research Hub in Acute Care with ethical approval provided by the East Midlands - Derby REC (reference: 20/EM/0158).

University Hospitals Birmingham NHS Foundation Trust (UHB), UK, is one of the largest hospital complexes in Europe, covering four NHS hospital sites, treating over 2.2 million patients per year, and housing the largest single critical care unit (CCU) in Europe. UHB provides secondary care to a diverse population of 1.3 million in Birmingham and Solihull, and provides a full range of tertiary services to the West Midlands region. UHB runs a fully electronic healthcare record (EHR) (PICS; Birmingham Systems), which has been in place since 1999. Data within PICS is time- and datestamped to the nearest millisecond, and includes all physiology and arterial blood gas analysis outputs.

\section{Case selection and data collection}

Between $1^{\text {st }}$ Jan 2017 and $18^{\text {th }}$ February 2021, data were collected for all measurements of oxygen saturation by oximetry and $A B G$ made during inpatient spells at UHB. From these, pairs of measurements ( $\mathrm{SpO} 2$ and $\mathrm{SaO} 2$ ) on the same patient taken within an interval of less than 20 minutes were identified. All consecutive measurements meeting these criteria were initially included in the study, to reduce the risk of selection bias as much as possible. In order to minimise the effect of within-spell correlation of outcomes, particularly for those patients with extended lengths of stay, only a single pair of measurements per spell were included in the analysis, namely the first valid pair of measurements after admission. Any cases with an $\mathrm{O} 2$ saturation by either measure of $<80 \%$ were subsequently excluded, as these were deemed likely to be spurious results (for example, misreported venous blood gas measurements for $\mathrm{SaO} 2$ ).

Patient demographics and clinical data were collected from the EHR and from mandatory data sets within the Hospital Trust. Ethnicity was self-reported by the patient or their family members on admission to hospital.

\section{O2 Saturation measurements}

ABG analysers automatically update the $\mathrm{EHR}$, with $\mathrm{SaO} 2$ measurements being recorded to one decimal place. No such linkage existed for pulse oximeters; hence SpO2 measurements were collected rounded to the nearest integer, and manually entered into the EHR by health care 
professionals. For the analyses of differences between the two approaches, calculations were made to one decimal place. However, for analysis of the absolute differences between approaches, the $\mathrm{SaO} 2$ values were rounded to the nearest integer, prior to calculations being performed. In addition, the exclusion criteria of $\mathrm{O} 2$ saturation $<80 \%$ used a value of $<79.5 \%$ for $\mathrm{SaO} 2$, for consistency with SpO2.

\section{Statistical methods}

Initially, measurements on $\mathrm{SpO} 2$ and $\mathrm{SaO} 2$ were compared using Wilcoxon's signed rank test, with the strength of the correlation quantified using Spearman's (rho) coefficient. Since 02 saturations are recorded as percentages, differences between $\mathrm{SpO} 2$ and $\mathrm{SaO} 2$ were reported as percentage point ( $p p$ ) differences. These were calculated as $\mathrm{SpO} 2$ minus $\mathrm{SaO} 2$, such that positive differences represented higher values on $\mathrm{SpO} 2$. To test for any proportional bias, the differences between $\mathrm{SpO} 2$ and $\mathrm{SaO} 2$ were also quantified within subgroups of $\mathrm{SaO} 2$ measurements. To model this relationship, a generalized additive model (GAM) was produced, with the $\mathrm{pp}$ difference between measures as the dependent variable, and the smooth function of the $\mathrm{SaO} 2$ as a continuous covariate. A second model was also produced with the $\mathrm{SpO} 2$ as the dependent variable. Since this followed a negatively skewed distribution, $\mathrm{SpO} 2$ values were subtracted from 101 to reverse the skew, before being $\log _{2^{-}}$ transformed, in order to normalise the distribution, and ensure reliability of the model.

Cohort characteristics and $\mathrm{O} 2$ saturations were then compared across groups of ethnicity using Kruskal-Wallis tests for continuous variables and Chi-square tests for nominal variables. The association between ethnicity and the differences between $\mathrm{SpO} 2$ and $\mathrm{SaO} 2$ were then further interrogated. Since the differences between $\mathrm{SpO} 2$ and $\mathrm{SaO} 2$ varied by the magnitude of the measurement, the previously described GAM model was extended to additionally include ethnicity as a nominal factor. This model was then further extended to adjust for the effects of other potentially confounding factors. The goodness of fit was assessed graphically for each factor, with transformations (e.g. $\log _{2}$ ) applied, where poor fit was identified.

Due to the complexities of modelling the relationship between $\mathrm{SpO} 2$ and $\mathrm{SaO} 2$, an alternative approach was also used as a sensitivity analysis. Here, $\mathrm{SaO} 2$ values were dichotomised, into hypoxic ( $\mathrm{SaO} 2<94.0 \%$ ) and normoxic ( $\mathrm{SaO} 2 \geq 94.0 \%$ ), with a threshold of $94.0 \%$ being selected since this is a commonly used clinical oxygenation threshold in acutely unwell patients without chronic respiratory disease. ${ }^{21}$ This was then set as the dependent variable in a binary logistic regression model, with $\mathrm{SpO} 2$ as a continuous covariate, and ethnicity as a nominal factor. To further assess the ability for $\mathrm{SpO} 2$ to identify hypoxia, the proportions of patients misclassified by $\mathrm{SpO} 2$, relative to $\mathrm{SaO} 2$, were calculated for each ethnicity, and compared using chi-square tests.

Continuous variables are reported as (arithmetic) mean \pm standard deviation (SD) where approximately normally distributed, or as median (interquartile range; IQR) otherwise. Analyses were performed using IBM SPSS 24 (IBM Corp. Armonk, NY), with GAM modelling performed using the R package " $\mathrm{mgcv}$ ". Cases with missing data were excluded from analyses of the affected variable, and $p<0.05$ was deemed to be indicative of statistical significance throughout. 


\section{Sample size calculation}

After exclusions, data were available for $\mathrm{N}=16818$ cases, with the differences between $\mathrm{SpO} 2$ and $\mathrm{SaO} 2$ having a standard deviation of 3.1pp (see Results section for further details). Based on these values, the study was sufficiently powered to detect a difference in the mean of $\mathrm{SpO} 2$ minus $\mathrm{SaO} 2$ between patients of White ( $81.2 \%$ of cohort) and Black (4.0\%) ethnicity of $0.4 \mathrm{pp}$, at $80 \%$ power and $5 \%$ alpha.

\section{Patient and public involvement}

This project was discussed by a multi-ethnic group of patients and members of the public, including the background and rationale for the project, the proposed analysis on the basis of self-defined ethnic groups and the results to date. There was overwhelming support for this work including the use of potentially sensitive data on ethnicity, given the clinical importance and public interest in the topic. This PPIE group will also help write lay summaries of the results to increase public awareness of the outputs.

\section{Results}

Cohort characteristics

Pairs of $\mathrm{SpO} 2$ and $\mathrm{SaO} 2$ measurements were available for a total of $\mathrm{N}=20231$ inpatient spells in $\mathrm{N}=18069$ patients. Of these, the ethnicity was not recorded in $\mathrm{N}=2612$ (12.9\%) spells, and these were excluded from further analysis. Of the remaining $\mathrm{N}=17619$ cases, $\mathrm{N}=689$ (3.9\%) had an $\mathrm{SaO} 2<80 \%$, and $\mathrm{N}=178(1.0 \%)$ had an $\mathrm{SpO} 2<80 \% ; \mathrm{N}=66(0.4 \%)$ of these had 02 saturations $<80 \%$ on both measures. The distributions of 02 saturations $<80 \%$ were similar across ethnicities $(p=0.077$, Supplementary Table 1). After excluding these cases, a total of $\mathrm{N}=16,818$ pairs of $\mathrm{O} 2$ saturation measurements were included in subsequent analysis (Figure 1).

The median patient age was 63 years (IQR: $50-74$ ), and $57.9 \%$ of cases were male. The majority of patients were of self-reported White ethnicity ( $\mathrm{N}=13649 ; 81.2 \%)$, with the remain der self-reporting Asian ( $N=1965 ; 11.7 \%$ ), Black ( $N=674 ; 4.0 \%$ ) or other (mixed non-White: $N=530 ; 3.2 \%$ ) ethnicities. See Table 1 for cohort demography and physiological data.

$\mathrm{O} 2$ saturations on $\mathrm{SpO} 2$ vs. SaO2

$\mathrm{O} 2$ saturations were found to follow a highly negatively skewed distribution; however, the shape of this distribution varied between measurement methods (Figure $2 a$ ). On SpO2, 30.2\% ( $\mathrm{N}=5087$ ) of cases had an 02 saturation of $100 \%$, compared to only $5.4 \%(\mathrm{~N}=915)$ of cases on $\mathrm{SaO} 2$ (i.e. SaO2 $299.5 \%$ ). The median SpO2 was $98 \%$ (IQR: $95-100 \%$ ), which was significantly higher than the 97.4\% (IQR: 95.6-98.7\%) on $\mathrm{SaO} 2(\mathrm{p}<0.001)$. The correlation between $\mathrm{SpO} 2$ and $\mathrm{SaO} 2$ was relatively modest, with Spearman's rho of 0.663 .

The differences in $\mathrm{O} 2$ saturations between measurement methods ( $\mathrm{SpO} 2$ minus $\mathrm{SaO} 2$ ) were assessed in further detail. These differences were approximately normally distributed, albeit with long tails, with a median difference of $0.5 p p$ (IQR: $-1.2,1.4$ ) and a mean difference of $0.1 \pm 3.1 p p$ (Figure $2 \boldsymbol{b}$ ). After rounding the $\mathrm{SaO} 2$ values to the nearest integer, $\mathrm{O} 2$ saturations were concordant 
on the two measurement approaches in only $17.3 \%(\mathrm{~N}=2910)$ of cases, with $\mathrm{SpO} 2$ giving the greater value in $47.6 \%(\mathrm{~N}=8,008)$, and $\mathrm{SaO} 2$ being greater in $35.1 \%(\mathrm{~N}=5,900)$.

The relationship between $\mathrm{SpO} 2$ and $\mathrm{SaO} 2$ was then assessed within subgroups of $\mathrm{SaO} 2$, in order to test for any proportional bias. This found the difference between measurement methods to vary with the magnitude, following a complex trend, which is visualised in Table 2 and Figure 3. For the lowest values of $\mathrm{SaO} 2$ (i.e. $<89.5 \%$ ), $\mathrm{SpO} 2$ tended to be greater than $\mathrm{SaO} 2$, with a median difference of 3.8pp (IQR: 0.4, 8.8). The size of this difference then reduced with increasing SaO2, with no significant difference between median measurements on $\mathrm{SpO} 2$ vs. $\mathrm{SaO} 2$ where $\mathrm{SaO} 2$ values were in the range $91.5-92.4 \%(p=0.639)$ or $92.5-93.4 \%(p=0.876)$. However, SpO2 subsequently began to underestimate, relative to $\mathrm{SaO} 2$, with a median difference of $-0.4 \mathrm{pp}$ (IQR: $-2.0,1.4 ; \mathrm{p}<0.001$ ) for the subgroup with $\mathrm{SaO} 2$ of $94.5-95.4 \%$. The direction of this effect then reversed again, with $\mathrm{SpO} 2$ tending to give higher values than $\mathrm{SaO} 2$ for the subgroup with $\mathrm{SaO} 2$ of $97.5-98.4 \%$ (median difference: 0.6pp; IQR: $-0.9,1.8$ ).

This subgroup analysis also showed discrepancies between the average difference when quantified as a mean or median. For example, within the subgroup of patients with a $\mathrm{SaO} 2$ of $98.5-99.4 \%$, the median difference was positive (0.7pp), implying measurements were higher on $\mathrm{SpO}$, whilst the mean difference was negative (-0.1pp), implying measurements were lower on SpO2. This occurred since, whilst the differences between methods was approximately normally distributed for the cohort as a whole (Figure $\mathbf{2 b}$ ), the distribution became negatively skewed for high $\mathrm{O} 2$ saturations, largely since there was an upper bound at an 02 saturation of $100 \%$. This is visualised in the ridgeline plot in Figure 4.

\section{Cohort characteristics by ethnicity}

Comparisons of patient characteristics across the groups of ethnicity found a significant difference in age $(p<0.001)$, with a median of 65 years in White patients, compared to medians of $50-57$ years in the non-White ethnic groups ( $<<0.001$, Table 1). A significant difference in the sex distribution was also observed $(p<0.001)$, with a greater preponderance of males in the Asian and "other" ethnic groups. Bilirubin was found to be significantly higher in White patients $(p<0.001)$, whilst those of Black ethnicity had significantly higher systolic BP $(p<0.001)$. The time intervals between $\mathrm{SpO} 2$ and $\mathrm{SaO} 2$ measurements were similar across the ethnicities, with the median absolute differences ranging from 7.5 to 7.6 minutes $(p=0.615)$.

\section{Differences in $\mathrm{O} 2$ saturations by ethnicity}

Whilst $\mathrm{SaO} 2$ was found to differ significantly between groups ( $p=0.001)$, the magnitude of this difference was relatively small, with medians ranging from $97.4 \%$ in White patients to $97.6 \%$ in the Asian group. However, the difference in $\mathrm{SpO} 2$ was more pronounced, with medians ranging from $97 \%$ in White patients, to $99 \%$ in Black patients $(p<0.001)$. As such, the differences between SpO2 and $\mathrm{SaO} 2$ varied significantly with ethnicity, with $\mathrm{SpO} 2$ being a median of $0.4 \mathrm{pp}$ higher than $\mathrm{SaO} 2$ in White patients, compared to $0.8 \mathrm{pp}$ higher in those of Black ethnicity $(p<0.001$, Table 1). 
Since the difference between $\mathrm{SpO} 2$ and $\mathrm{SaO} 2$ had previously been shown to vary by the magnitude of the measurement, analyses were then performed to compare this between ethnicities, after adjusting for magnitude of $\mathrm{SaO} 2$. The resulting model (Figure $5 a$ ) found the significant difference between ethnicities to persist, after adjusting for the magnitude of the measurement $(p<0.001)$. Relative to patients of White ethnicity, the differences between $\mathrm{SpO} 2$ and $\mathrm{SaO} 2$ were $0.5 \mathrm{pp}(95 \% \mathrm{Cl}$ : $0.4-0.7, p<0.001)$ greater in Asian patients, $0.8 \mathrm{pp}(0.6-1.0, \mathrm{p}<0.001)$ greater in Black patients, and $0.3 p p(0.1-0.6, p=0.006)$ greater in those other ethnicities.

This model was then further extended, to adjust for other potentially confounding factors (Table 3). This found the difference in $\mathrm{O} 2$ saturations ( $\mathrm{SpO} 2$ minus $\mathrm{SaO} 2$ ) to be significantly more positive in males $(p<0.001)$, younger patients $(p<0.001)$, those with lower $\mathrm{COHb}(p<0.001)$, and those with higher systolic BP ( $p=0.041)$. After adjusting for these factors, the differences between ethnicities remained significant $(p<0.001)$, with more positive differences between measures of 02 saturations observed for Asian (0.3pp, $p<0.001$ ) and Black $(0.6 p p, p<0.001)$ patients, relative to those of White ethnicity.

\section{Associations between SpO2 and normoxia by ethnicity}

Due to the complexities of modelling the relationship between $\mathrm{SpO} 2$ and $\mathrm{SaO} 2$, the analysis of ethnicity was repeated using an alternative approach as a sensitivity analysis. Initially, the $\mathrm{SaO} 2$ values were dichotomised using a cut-off value of $94.0 \%$, with the $N=14,165$ (84.2\%) of cases that were greater than or equal to this threshold being classified as normoxic, and the remainder as hypoxic. A binary logistic regression model was then produced, to assess the relationship between $\mathrm{SpO} 2$ and normoxia on $\mathrm{SaO} 2$ (Figure 6a). This model was then extended to include ethnicity as a factor (Figure 6b, Table 4, Table 5), which was found to be statistically significant $(p<0.001)$. For a given $\mathrm{SpO} 2$ value, both Asian (odds ratio [OR]: 0.75, $p<0.001$ ) and Black (OR: 0.67, p=0.003) patients were significantly less likely to be normoxic, compared to those of White ethnicity, implying a greater tendency for $\mathrm{SpO} 2$ to overestimate $\mathrm{O} 2$ saturations in these non-White groups

In order to further quantify this effect, a misclassification analysis was performed (Table 6). For the cohort as a whole, $41.5 \%$ (1251/3013) of those with SpO2<94\% had been misclassified, and were actually normoxic on $\mathrm{SaO} 2$; this rate was similar across the subgroups of ethnicities $(\mathrm{p}=0.982)$. In those with $\mathrm{SpO} 2 \geq 94 \%$, a total of $6.5 \%(891 / 13805)$ had been misclassified, and were hypoxic on $\mathrm{SaO} 2$. This rate was found to differ significantly with ethnicity ( $\mathrm{p}=0.007$ ), with SpO2 misclassifying $6.1 \%(680 / 11117)$ of White patients as normoxic, compared to $8.7 \%(51 / 583)$ of Black patients.

\section{Discussion}

This study reports paired oxygen saturation measurements from pulse oximetry and ABG (the accepted gold standard) from almost 17000 inpatient spells at a secondary care NHS trust with four hospitals, which serves a large diverse urban catchment area. This is the largest study conducted to assess this issue, to date. 
The relationship between $\mathrm{SpO} 2$ and $\mathrm{SaO} 2$ measurements was complex, and varied across the $\mathrm{O} 2$ saturation spectrum ( $80 \%$ to $100 \%$ ). At lower values of 02 saturation ( $\mathrm{SaO} 280 \%-91.4 \%$ ), SpO2 considerably overestimated oxygenation (relative to $\mathrm{SaO} 2$ ). At higher values ( $\mathrm{SaO} 2$ 93.5-97.4\%), $\mathrm{SpO} 2$ considerably underestimated $\mathrm{O} 2$ saturation. These differences were exaggerated in measurements taken from Black ethnic groups, and misclassification (classified as normoxic when hypoxic) occurred significantly more often in this group compared to those of White ethnicity. Similar (albeit smaller) effects were observed in those of Asian ethnicity compared to White patients. Despite the complex relationship between $\mathrm{SpO} 2$ and $\mathrm{SaO} 2$, these differences between ethnicities appeared to persist over the range of $\mathrm{O} 2$ saturations.

The discrepancies at low oxygen saturations are likely to be clinically significant and the impact could be important. An $\mathrm{SaO} 2$ reading of $86 \%$ was often associated with a falsely reassuring $\mathrm{SpO} 2$ of $>90 \%$, leaving hypoxaemia potentially undetected and untreated. Analysis of misclassification types suggests that $\mathrm{SpO} 2$ measurements that impact a reduction in oxygen therapy are less affected across ethnicities than scenarios where oxygen therapy may need to be applied or escalated.

Our results are consistent with a much smaller study of 11 healthy people with darkly pigmented skin and 10 healthy people with light skin pigmentation, who were oxygen restricted as part of a physiological study. This study tested three different pulse oximeters, all of which gave higher readings, relative to $\mathrm{SaO} 2$, in those with dark-vs. light-pigmented skin. ${ }^{22} \mathrm{~A}$ larger follow-on study of 36 participant replicated these findings and, importantly, highlighted differences in performance of devices and variations amongst differing levels of skin pigmentation (dark, light and intermediate). This is replicated in our findings of Asian participants having less discrepancy than Black participants. Our results are also consistent with results from a large study reported in $2020^{12}$. They reported paired measures of oxygen saturation by pulse oximetry and $A B G$ obtained from two cohorts: one comprising 1333 White patients and 276 Black patients from 2020, and one multi-centre cohort comprising 7342 White patients and 1050 Black patients from 2014 - 2015, finding a consistent difference of $2 \%$ across the spectrum of SpO2 measurements in Black compared to White patients. Our study not only includes patients of all ethnicities, but also contains a more detailed statistical analysis of the relationship between $\mathrm{SpO} 2$ and $\mathrm{SaO} 2$ at different clinically relevant cut-off values of SpO2.

Strengths of our study include its size and representation of a multi-cultural, urban population in the UK across 4 hospital sites. The primary limitation of this study was its retrospective nature, with the baseline cohort comprising patients who had undergone assessment of $\mathrm{O} 2$ saturation by both oximetry and $A B G$, which may not be representative of the inpatient cohort as a whole. In addition, initial assessment of the data identified $\mathrm{O} 2$ saturations that were unfeasibly low, and likely to represent either erroneous or incorrectly recorded measurements. In an attempt to exclude these spurious values, a minimum 02 saturation of $80 \%$ on both oximetry and $A B G$ was selected as a threshold, with measurements below this being excluded. However, if this approach is too strict, then genuine measurements may have been excluded, introducing selection bias, whereas if it was too lenient, then erroneous data may have been included in the analysis. 
A second limitation of the study is the potential for confounding, due to the differences in baseline characteristics between the ethnicity groups, for example, the large difference in average age. This age discrepancy has been described in other studies of hospitalised patients where ethnicity was a focus $^{23}$ and, therefore, may reflect true differences in admitted populations, but this could impact on the results of the current study. Whilst multivariable analyses were employed to adjust for these differences, modelling will always leave some degree of residual confounding. There is also the potential for other intangible or unmeasured confounding factors to have influenced the findings of the analysis. Thirdly, the $\mathrm{SpO} 2$ and $\mathrm{SaO} 2$ readings were separated by on average 7.5 minutes and were not all simultaneous readings. There is a degree of $\mathrm{SpO} 2$ dynamic variation, especially in acutely ill patients that this study design could not account for. Fourthly, the self-reported groups of ethnicity used in the analysis were reasonably broad. As such, whilst these may act as a surrogate of skin colour, there is likely to be considerably within-group variability. If the observed discrepancies in oximetry measurements, relative to $\mathrm{SaO} 2$ are, to some degree, a consequence of the degree of skin pigmentation, then this may have acted as a confounding factor in the analysis. Finally, the data included in the study comprised inpatient spells from hospitals based in the same geographical area and operated under the same NHS trust. As such, the results may not be generalizable to other hospitals, particularly if there are large differences in patient demographics.

Health inequalities due to ethnicity have been highlighted during the COVID-19 pandemic ${ }^{23}$. There is an increasing drive for early discharges from hospital, as well as for remote home monitoring to avoid unnecessary admissions ${ }^{2425}$. Pulse oximetry is used routinely in all healthcare settings, and is the mainstay of rapid quantification of a patient's oxygenation status. Although $\mathrm{O} 2$ saturations measured on pulse oximetry should never be used in isolation for clinical decision-making, they are included in many severity scoring systems and decision-making algorithms, such as those for pneumonia and COPD. Our findings highlight the need for some caution, as there is potential risk of overestimation of $\mathrm{SpO} 2$ measurement, which appears to be particularly pronounced in patients in ethnicities with a tendency for darker skin pigmentation. This could potentially lead to inadequate treatment if, for example, insufficient oxygenation in patients COVID-19 is missed, leading to patients being sent home, rather than admitted, potentially delaying or denying access to evidencebased therapies.

\section{Conclusions}

This study highlights differences in the measurement of oxygenation status when using pulse oximeters and arterial blood gases. Discrepancies are largest when oxygen saturations are lowest, where $\mathrm{SpO} 2$ consistently overestimates $\mathrm{SaO} 2$. Across the range of $\mathrm{O} 2$ saturations, the difference between $\mathrm{SpO} 2$ and $\mathrm{SaO} 2$ is exaggerated in those of Black ethnicity, potentially placing them at most risk of undetected hypoxic events. Whilst there is insufficient evidence to change current practice, caution may need to be exercised in some small, specific subgroups of patients with borderline SpO2 levels. Prospective studies are urgently warranted to further quantify the degree of any such racial bias in current devices, to ensure care is optimised for all.

Word count 4995 


\section{Research in Context}

\section{Evidence before this study}

We searched PubMed for studies of ethnic disparities in oxygen saturations, published up to Sept 31, 2021. We used the search terms (["Ethnicity" or "Racial”] and ["Oximetry" OR "Saturations" OR "Oxygen"]). We found one large study from US centres reporting paired measures of oxygen saturation by pulse oximetry and ABG obtained from two cohorts: one comprising 1333 White patients and 276 Black patients and one multi-centre cohort comprising 7342 White patients and 1050 Black patients from $2014-2015$, finding a consistent difference of $2 \%$ across the spectrum of SpO2 measurements in Black compared to White patients. Other studies have been small and in defined disease states. Disparities in all ethnic groups and differences at clinically relevant cut-off values of $\mathrm{SpO} 2$ remain unconfirmed yet important due to the widespread use of pulse oximetry in clinical decision making for admission and discharge to hospital.

\section{Added Value of this Study}

This is the largest cohort study in a diverse cohort in terms of ethnicity, over a significant period and in a spectrum of acute illness severity and admission reason. Providing real-life and internationally translatable data. We highlight differences in the measurement of oxygenation status when using pulse oximeters and arterial blood gases. Discrepancies are largest when oxygen saturations are lowest, where $\mathrm{SpO} 2$ consistently overestimates $\mathrm{SaO} 2$. Across the range of $\mathrm{O} 2$ saturations, the difference between $\mathrm{SpO} 2$ and $\mathrm{SaO} 2$ is exaggerated in those of Black ethnicity, potentially placing them at most risk of undetected hypoxic events. Similar but smaller effects were observed in those of Asian ethnicity compared to White patients. Despite the complex relationship between $\mathrm{SpO} 2$ and $\mathrm{SaO} 2$, these differences between ethnicities appeared to persist over the range of $\mathrm{O} 2$ saturations.

\section{Implications of all the available evidence}

Our findings and others suggest that validation of pulse oximeters should focus on non-White racial populations, in order to identify any shortcomings and drive technological refinements. Whilst newer and more accurate devices are being developed, we urge companies and regulatory authorities to provide performance characteristics across ethnicities, and quantify any bias that may be present, so that clinicians can be fully informed in decision-making.

\section{Ethical Statement}

\section{Ethical Approval}

This data study was supported by PIONEER, a Health Data Research Hub in Acute Care with ethical approval provided by the East Midlands - Derby REC (reference: 20/EM/0158).

\section{Data Availability Statement}

Data is available upon reasonable application to the PIONEER Hub. All data access applications will be reviewed in accordance with the PIONEER ethical approvals and governance processes.

Contributors: DP, MB, and ES were responsible for the study design. JH, SG, FC did the data analyses. $D P, E S$, and JH drafted the manuscript, and all authors contributed to critical revision of the manuscript for important intellectual content and approved it for submission. DP and ES are the 
medRxiv preprint doi: https://doi.org/10.1101/2021.11.21.21266662; this version posted November 26, 2021. The copyright holder for this preprint (which was not certified by peer review) is the author/funder, who has granted medRxiv a license to display the preprint in perpetuity.

It is made available under a CC-BY-NC-ND 4.0 International license .

guarantors. The corresponding author attests that all listed authors meet authorship criteria and that no others meeting the criteria have been omitted.

Competing interests: All authors have completed the ICMJE uniform disclosure form at www.icmje.org/coi_disclosure.pdf and declare: DP reports funding from the NIHR and MRC. ES reports funding support from HDR-UK, MRC, Wellcome Trust, NIHR, Alpha-1-Foundation and British Lung Foundation. ES declares receiving consulting fees from Boehringer Ingleheim and support to attend scientific meetings from Astra Zeneca. MB reports funding from the UK Intensive Care Society

The lead author affirms that this manuscript is an honest, accurate, and transparent account of the study being reported; that no important aspects of the study have been omitted; and that any discrepancies from the study as planned (and, if relevant, registered) have been explained. 
Table 1 - Cohort characteristics by ethnicity

\begin{tabular}{|c|c|c|c|c|c|c|c|}
\hline & \multirow[b]{2}{*}{$\mathbf{N}$} & \multirow{2}{*}{$\begin{array}{c}\text { Total } \\
\text { Cohort }\end{array}$} & \multicolumn{4}{|c|}{ Ethnicity } & \multirow[b]{2}{*}{ p-Value } \\
\hline & & & White & Asian & Black & Other & \\
\hline Age (Years) & 16818 & $63(50,74)$ & $65(53,75)$ & $57(42,68)$ & $55(45,68)$ & $50(35,64)$ & $<0.001$ \\
\hline$<50$ & & $4101(24.4 \%)$ & $2878(21.1 \%)$ & $729(37.1 \%)$ & $231(34.3 \%)$ & $263(49.6 \%)$ & \\
\hline $50-64$ & & $4700(27.9 \%)$ & $3740(27.4 \%)$ & $578(29.4 \%)$ & $243(36.1 \%)$ & $139(26.2 \%)$ & \\
\hline $65-74$ & & $4045(24.1 \%)$ & $3556(26.1 \%)$ & $348(17.7 \%)$ & $67(9.9 \%)$ & $74(14.0 \%)$ & \\
\hline $75-84$ & & $2866(17.0 \%)$ & $2506(18.4 \%)$ & $235(12.0 \%)$ & $85(12.6 \%)$ & $40(7.5 \%)$ & \\
\hline $85+$ & & $1106(6.6 \%)$ & $969(7.1 \%)$ & $75(3.8 \%)$ & $48(7.1 \%)$ & $14(2.6 \%)$ & \\
\hline Sex (\% Male) ${ }^{*}$ & 16815 & 9735 (57.9\%) & $7796(57.1 \%)$ & $1217(61.9 \%)$ & $388(57.6 \%)$ & $334(63.0 \%)$ & $<0.001$ \\
\hline FiO2 (fraction of inspired air) & 16733 & $0.28(0.21,0.40)$ & $0.28(0.21,0.40)$ & $0.28(0.21,0.45)$ & $0.28(0.21,0.40)$ & $0.28(0.21,0.45)$ & $<0.001$ \\
\hline $\mathrm{PaO} 2(\mathrm{kPa})^{* *}$ & 16543 & $12.7(10.0,17.6)$ & $12.6(10.0,17.4)$ & $13.4(10.2,19.0)$ & $12.9(10.2,18.8)$ & $13.0(10.1,18.3)$ & $<0.001$ \\
\hline Bilirubin $(\mu \mathrm{mol} / \mathrm{L})$ & 16488 & $10(7,17)$ & $10(7,18)$ & $9(6,15)$ & $9(6,15)$ & $10(7,17)$ & $<0.001$ \\
\hline Systolic BP ( $\mathrm{mmHg})$ & 15948 & $124 \pm 26$ & $124 \pm 26$ & $124 \pm 26$ & $132 \pm 29$ & $125 \pm 26$ & $<0.001$ \\
\hline MetHb (\%) & 16680 & $0.6(0.5,0.7)$ & $0.6(0.5,0.7)$ & $0.6(0.5,0.7)$ & $0.6(0.5,0.7)$ & $0.6(0.5,0.7)$ & 0.631 \\
\hline $\mathrm{COHb}(\%)$ & 16681 & $1.4(1.1,1.7)$ & $1.4(1.1,1.7)$ & $1.2(0.9,1.5)$ & $1.3(1.1,1.7)$ & $1.3(1.1,1.6)$ & $<0.001$ \\
\hline \multicolumn{8}{|l|}{ Time SpO2 to SaO2 (Minutes) } \\
\hline $\mathrm{SaO} 2$ Minus SpO2 & 16818 & $0.0(-7.4,7.8)$ & $0.0(-7.5,7.8)$ & $0.0(-6.9,8.0)$ & $0.0(-7.0,8.1)$ & $0.0(-8.0,7.3)$ & 0.639 \\
\hline Absolute Difference & 16818 & $7.6(2.9,13.0)$ & $7.6(2.9,13.0)$ & $7.5(2.6,12.9)$ & $7.6(3.0,12.8)$ & $7.5(3.2,13.1)$ & 0.615 \\
\hline \multicolumn{8}{|l|}{ O2 Saturation (\%) } \\
\hline $\mathrm{SaO2}$ & 16818 & $97.4(95.6,98.7)$ & $97.4(95.6,98.6)$ & $97.6(95.6,98.8)$ & $97.5(95.7,98.8)$ & $97.6(95.6,98.8)$ & 0.001 \\
\hline $\mathrm{SpO} 2$ & 16818 & $98(95,100)$ & $97(95,100)$ & $98(95,100)$ & $99(96,100)$ & $98(95,100)$ & $<0.001$ \\
\hline \multicolumn{8}{|l|}{ Difference in 02 Saturation (pp) } \\
\hline $\mathrm{SpO} 2$ Minus SaO2 & 16818 & $0.5(-1.2,1.4)$ & $0.4(-1.3,1.4)$ & $0.7(-0.7,1.5)$ & $0.8(-0.3,1.9)$ & $0.7(-1.0,1.6)$ & $<0.001$ \\
\hline Absolute Difference ${ }^{* * *}$ & 16818 & $1(1,3)$ & $1(1,3)$ & $1(1,2)$ & $1(1,3)$ & $1(1,3)$ & 0.348 \\
\hline
\end{tabular}

Continuous variables are reported as median (interquartile range) or mean \pm standard deviation, with $p$-values from Kruskal-Wallis tests. Nominal variables are reported as $N$ (column \%), with p-values from Chi-square tests. Bold p-values are significant at $p<0.05$. *vs. female - excludes $N=3$ who identified as NonBinary. **Temperature-corrected. *** SaO2 values were rounded to the nearest integer when calculating absolute differences, for consistency with the SpO2 measurements. $p p=$ percentage points; SaO2=arterial 02 saturation; SpO2=O2 saturation on oximetry. FiO2=fraction of inspired oxygen; PaO2=partial pressure of oxygen; $B P=$ blood pressure; MetHb=methaemoglobin; $\mathrm{COH} b=$ carboxyhaemoglobin. 
medRxiv preprint doi: https://doi.org/10.1101/2021.11.21.21266662; this version posted November 26, 2021. The copyright holder for this preprint (which was not certified by peer review) is the author/funder, who has granted medRxiv a license to display the preprint in perpetuity.

It is made available under a CC-BY-NC-ND 4.0 International license .

Table 2 - Associations between SaO2 and SpO2

\begin{tabular}{|l|r|cc|c|r|}
\hline & \multicolumn{1}{|c|}{$\boldsymbol{N}$} & \multicolumn{2}{|c|}{$\begin{array}{c}\text { Difference in O2 Saturation } \\
\text { (SpO2 minus SaO2; pp) }\end{array}$} & $\begin{array}{c}\text { O2 } \\
\text { Saturation }\end{array}$ & \\
\hline SaO2 (\%) & \multicolumn{1}{c|}{ Pairs } & Mean \pm SD & Median (IQR) & Higher on*: & p-Value \\
\hline 89.5 & 952 & $4.7 \pm 5.6$ & $3.8(0.4,8.8)$ & SpO2 & $<0.001$ \\
$89.5-90.4$ & 247 & $1.4 \pm 4.0$ & $1.1(-1.4,3.9)$ & SpO2 & $<0.001$ \\
$90.5-91.4$ & 308 & $0.8 \pm 3.8$ & $0.6(-1.8,3.1)$ & SpO2 & $\mathbf{0 . 0 0 2}$ \\
$91.5-92.4$ & 369 & $0.2 \pm 3.5$ & $-0.2(-2.2,2.3)$ & NS & 0.639 \\
$92.5-93.4$ & 487 & $0.0 \pm 3.3$ & $-0.2(-2.0,1.9)$ & NS & 0.876 \\
$93.5-94.4$ & 631 & $-0.4 \pm 3.2$ & $-0.3(-2.2,1.7)$ & SaO2 & $\mathbf{0 . 0 1 3}$ \\
$94.5-95.4$ & 1029 & $-0.4 \pm 3.1$ & $-0.4(-2.0,1.4)$ & SaO2 & $<0.001$ \\
$95.5-96.4$ & 1351 & $-0.4 \pm 2.8$ & $-0.2(-1.8,1.6)$ & SaO2 & $<0.001$ \\
$96.5-97.4$ & 3128 & $-0.3 \pm 2.5$ & $-0.1(-1.6,1.5)$ & SaO2 & $\mathbf{0 . 0 2 1}$ \\
$97.5-98.4$ & 3311 & $0.1 \pm 2.2$ & $0.6(-0.9,1.8)$ & SpO2 & $<0.001$ \\
$98.5-99.4$ & 4090 & $-0.1 \pm 2.2$ & $0.7(-0.5,1.1)$ & SpO2 & $<0.001$ \\
$\geq 99.5$ & 915 & $-0.8 \pm 2.7$ & $0.3(-0.6,0.5)$ & NS & 0.456 \\
\hline
\end{tabular}

Subgroup analyses were performed within intervals of SaO2. For each subgroup, the percentage point (pp) differences between $\mathrm{SpO} 2$ and $\mathrm{SaO} 2$ are reported as both mean \pm standard deviation (SD), and as median (interquartile range; IQR), and compared using Wilcoxon's test. Bold p-values are significant at $p<0.05$. *The measure with the higher 02 saturation, based on the sums of positive vs. negative ranks from the Wilcoxon's test. NS = no significant difference; SaO2=arterial O2 saturation; $\mathrm{SpO2}=02$ saturation on oximetry; $p p=$ percentage points 
Table 3 - Associations with percentage point differences in 02 saturation between SpO2 and SaO2

\begin{tabular}{|c|c|c|c|c|c|c|}
\hline & \multicolumn{2}{|c|}{ Analysis 1) Univariable } & \multicolumn{2}{|c|}{ Analysis 2) SaO2 + Ethnicity } & \multicolumn{2}{|c|}{ Analysis 3) All Factors } \\
\hline & Coefficient (95\% CI) & $p$-Value & Coefficient (95\% Cl) & $p$-Value & Coefficient (95\% Cl) & $p$-Value \\
\hline $\mathrm{SaO} 2$ & $N / A^{*}$ & $<0.001$ & $N / A^{*}$ & $<0.001$ & $N / A^{*}$ & $<0.001$ \\
\hline Ethnicity & & $<0.001$ & & $<0.001$ & & $<0.001$ \\
\hline White & - & - & - & - & - & - \\
\hline Asian & $0.49(0.34,0.63)$ & $<0.001$ & $0.53(0.40,0.67)$ & $<0.001$ & $0.33(0.19,0.47)$ & $<0.001$ \\
\hline Black & $0.83(0.59,1.07)$ & $<0.001$ & $0.78(0.56,0.99)$ & $<0.001$ & $0.62(0.40,0.84)$ & $<0.001$ \\
\hline Other & $0.33(0.07,0.60)$ & 0.015 & $0.33(0.09,0.57)$ & 0.006 & $0.11(-0.14,0.35)$ & 0.394 \\
\hline Age (per Decade) & $-0.12(-0.15,-0.09)$ & $<0.001$ & & & $-0.20(-0.22,-0.17)$ & $<0.001$ \\
\hline Sex (Male) & $0.03(-0.06,0.13)$ & 0.509 & & & $0.15(0.07,0.24)$ & $<0.001$ \\
\hline Bilirubin (per Two-Fold Increase)** & $-0.05(-0.08,-0.01)$ & 0.015 & & & $0.01(-0.03,0.04)$ & 0.630 \\
\hline Systolic BP (per $10 \mathrm{mmHg}$ ) & $0.03(0.01,0.05)$ & $<0.001$ & & & $0.02(0.00,0.03)$ & 0.041 \\
\hline $\mathrm{COHb}$ (per 10pp) & $-1.14(-1.70,-0.59)$ & $<0.001$ & & & $-3.11(-3.64,-2.59)$ & $<0.001$ \\
\hline Time from SpO2 to $\mathrm{SaO} 2$ (per 10 mins) & $-0.03(-0.08,0.01)$ & 0.172 & & & $-0.01(-0.05,0.04)$ & 0.745 \\
\hline
\end{tabular}

Results are reported for three analyses, each of which had the percentage point (pp) difference between SpO2 and SaO2 as the dependent variable, with positive values implying a higher measurement on SpO2. Coefficients represent the change in this difference per the stated number of units increase in continuous variables, or for the stated category relative to the reference category for nominal variables. In Analysis 1), a separate univariable model was produced for each factor, with a generalized additive model (GAM) used for SaO2, and general linear models used for the other factors considered. Analysis 2) then extended the GAM of SaO2 to include ethnicity, whilst Analysis 3) further extended this model to include all factors reported in the table. For Analysis 3), only the $\mathrm{SaO} 2$ was modelled based on a smooth function, as goodness of fit testing indicated that linear models yielded a reasonable fit for the other factors considered. The numbers of cases included in each model in Analysis 1), after excluding those with missing data, are as per the N's in Table 1.

Analysis 3) used a complete-cases approach, and was based on $N=15494$ after exclusions. Bold p-values are significant at $p<0.05$. *Since SaO2 was modelled as a smooth function in the GAM, it was not possible to summarise this trend using a single coefficient; this is instead visualised in Figure $3 b$ for Analysis 1 ) and Figure 5a for Analysis 2. **Since bilirubin followed a highly skewed distribution, and had a non-linear association with the dependent variable, values were $\log _{2}$-transformed, prior to analysis; hence the coefficient represents the change in the outcome per two-fold increase in bilirubin levels. SaO2=arterial $O 2$ saturation; $\mathrm{SPO}=\mathrm{O} 2$ saturation on oximetry; $\mathrm{COH} b=$ carboxyhaemoglobin; $\mathrm{BP}=$ blood pressure; $p p=$ percentage point. 
medRxiv preprint doi: https://doi.org/10.1101/2021.11.21.21266662; this version posted November 26, 2021. The copyright holder for this preprint (which was not certified by peer review) is the author/funder, who has granted medRxiv a license to display the preprint in perpetuity.

It is made available under a CC-BY-NC-ND 4.0 International license .

Table 4 - Binary logistic regression model of normoxia (SaO2 $\geq 94.0 \%$ )

\begin{tabular}{|c|c|c|}
\hline & Odds Ratio (95\% Cl) & p-Value \\
\hline Sp02 (per pp) & $1.50(1.48-1.53)$ & $<0.001$ \\
\hline Ethnicity & & $<0.001$ \\
\hline White & - & - \\
Asian & $0.75(0.64-0.88)$ & $<0.001$ \\
Black & $0.67(0.51-0.87)$ & $\mathbf{0 . 0 0 3}$ \\
Other & $0.86(0.63-1.16)$ & 0.322 \\
\hline
\end{tabular}

Results are from a binary logistic regression model, with $\mathrm{SaO} 2 \geq 94.0 \%$ as the dependent variable. $\mathrm{SpO} 2$ was included as a continuous covariate, alongside ethnicity. The model was based on $N=16818$ $(\mathrm{N}=14165$ events). Bold $p$-values are significant at $p<0.05$. $p p=$ percentage point. SaO2=arterial 02 saturation; $\mathrm{SpO} 2=02$ saturation on oximetry.

Table 5 - Association between SpO2 and rates of normoxia (SaO2 $\geq 94.0 \%$ ) by ethnicity

\begin{tabular}{|c|cccc|}
\hline & \multicolumn{4}{|c|}{ Cases With SaO2 $\geq 94.0 \%$} \\
SpO2 & White & Asian & Black & Other \\
\hline$<90 \%$ & $23.4 \%(197 / 843)$ & $29.6 \%(24 / 81)$ & $24.2 \%(8 / 33)$ & $25.0 \%(10 / 40)$ \\
$90 \%$ & $31.8 \%(100 / 314)$ & $31.3 \%(10 / 32)$ & $29.4 \%(5 / 17)$ & $54.5 \%(6 / 11)$ \\
$91 \%$ & $41.1 \%(139 / 338)$ & $21.4 \%(9 / 42)$ & $70.0 \%(7 / 10)$ & $50.0 \%(2 / 4)$ \\
$92 \%$ & $53.2 \%(280 / 526)$ & $49.4 \%(40 / 81)$ & $40.0 \%(6 / 15)$ & $50.0 \%(7 / 14)$ \\
$93 \%$ & $65.4 \%(334 / 511)$ & $63.8 \%(44 / 69)$ & $68.8 \%(11 / 16)$ & $75.0 \%(12 / 16)$ \\
$94 \%$ & $78.8 \%(651 / 826)$ & $76.6 \%(72 / 94)$ & $75.0 \%(18 / 24)$ & $78.3 \%(18 / 23)$ \\
$95 \%$ & $86.9 \%(936 / 1077)$ & $80.0 \%(88 / 110)$ & $72.7 \%(24 / 33)$ & $69.7 \%(23 / 33)$ \\
$96 \%$ & $91.0 \%(1140 / 1253)$ & $86.7 \%(124 / 143)$ & $89.4 \%(42 / 47)$ & $86.0 \%(43 / 50)$ \\
$97 \%$ & $94.7 \%(1183 / 1249)$ & $87.6 \%(156 / 178)$ & $88.5 \%(46 / 52)$ & $90.5 \%(38 / 42)$ \\
$98 \%$ & $95.7 \%(1474 / 1541)$ & $94.9 \%(186 / 196)$ & $92.3 \%(60 / 65)$ & $93.5 \%(43 / 46)$ \\
$99 \%$ & $97.1 \%(1288 / 1327)$ & $95.8 \%(183 / 191)$ & $93.7 \%(74 / 79)$ & $94.9 \%(37 / 39)$ \\
$100 \%$ & $97.9 \%(3765 / 3844)$ & $97.2 \%(727 / 748)$ & $94.7 \%(268 / 283)$ & $97.6 \%(207 / 212)$ \\
\hline
\end{tabular}

Data were initially divided into subgroups, based on the value of SpO2. Within each subgroup, the \% $(n / N)$ of patients with $\mathrm{SaO} 2 \geq 94.0 \%$ is then reported for each ethnicity. SaO2=arterial $\mathrm{O} 2$ saturation; SpO2=O2 saturation on oximetry. 
medRxiv preprint doi: https://doi.org/10.1101/2021.11.21.21266662; this version posted November 26, 2021. The copyright holder for this preprint (which was not certified by peer review) is the author/funder, who has granted medRxiv a license to display the preprint in perpetuity.

It is made available under a CC-BY-NC-ND 4.0 International license .

Table 6 - Misclassification analysis

\begin{tabular}{|cc|cc|}
\hline \multirow{2}{*}{ Subgroup } & SpO2 & $\begin{array}{c}\text { Hypoxia } \\
\text { (SaO2 }<94.0 \%)\end{array}$ & $\begin{array}{c}\text { Normoxia } \\
\text { (SaO2 } \geq 94.0 \%)\end{array}$ \\
\hline \multirow{2}{*}{ Overall } & $<94 \%$ & $1762(58.5 \%)$ & $1251(41.5 \%)$ \\
& $\geq 94 \%$ & $891(6.5 \%)$ & $12914(93.5 \%)$ \\
\hline \multirow{3}{*}{ By Ethnicity } \\
\hline \multirow{2}{*}{ Asian } & $<94 \%$ & $1482(58.5 \%)$ & $1050(41.5 \%)$ \\
& $\geq 94 \%$ & $680(6.1 \%)$ & $10437(93.9 \%)$ \\
\hline \multirow{2}{*}{ Black } & $<94 \%$ & $178(58.4 \%)$ & $127(41.6 \%)$ \\
& $<94 \%$ & $54(59.3 \%)$ & $37(40.7 \%)$ \\
\multirow{2}{*}{ Other } & $<94 \%$ & $51(8.7 \%)$ & $532(91.3 \%)$ \\
& $\geq 94 \%$ & $38(56.5 \%)$ & $37(43.5 \%)$ \\
& $36(8.1 \%)$ & $409(91.9 \%)$ \\
\hline
\end{tabular}

Cases were initially classified as hypoxic or normoxic, based on SaO2. The distribution of hypoxia vs. normoxia was then calculated within those cases with SpO2 <94\% and $\geq 94 \%$ for the cohort as a whole, as well as within each subgroup of ethnicity. Data are reported as $N$ (row \%). 


\section{Figure Legends}

\section{Figure 1 - Study flowchart}

\section{Figure 2 - Distributions of SaO2 and SpO2}

In Figure A, points represent the proportion of cases with each integer value of $\mathrm{O} 2$ saturation; $\mathrm{SaO} 2$ values were rounded to the nearest integer before plotting. Figure $B$ is a histogram of the percentage point ( $p p$ ) differences in $\mathrm{SpO} 2$ minus $\mathrm{SaO} 2$ (with $\mathrm{SaO} 2$ values rounded to the nearest integer). Each bar represents 1 pp of $\mathrm{O} 2$ saturation, with the black bar representing concordance between SpO2 and $\mathrm{SaO} 2$ (i.e. a difference of zero). SaO2=arterial $\mathrm{O} 2$ saturation; $\mathrm{SpO} 2=02$ saturation on oximetry

\section{Figure 3 - Association between $\mathrm{SaO} 2$ and $\mathrm{SpO} 2$}

Points represent the median $\mathrm{SpO} 2$ within intervals of SaO2. The first point includes $\mathrm{SaO} 2$ measurements $<89.5 \%$, with subsequent intervals having a width of 1 percentage point $(89.5-90.4 \%$, 90.5-91.4\% etc.). Whiskers represent the $2.5^{\text {th }}$ and $97.5^{\text {th }}$ percentiles, hence the range comprising $95 \%$ of values. Red lines are from generalized additive models (GAMs), with the smooth function of SaO2 as the independent variable, and either $\log _{2}(101-5 p O 2)$ or the percentage point difference between $\mathrm{SpO} 2$ and $\mathrm{SaO} 2$ as the dependent variable. *The $\mathrm{O} 2$ saturation on $\mathrm{SpO} 2$ minus SaO2, as a percentage point (pp) difference. $\mathrm{SaO2}=$ arterial $\mathrm{O} 2$ saturation; $\mathrm{SpO} 2=02$ saturation on oximetry.

Figure 4-Ridgeline plot of the differences in 02 saturations by $\mathrm{SaO} 2$ Lines represent the distributions of the differences in $\mathrm{O} 2$ saturations within subgroups of $\mathrm{SaO} 2$, and are truncated at the minimum and maximum observed values. *Differences in 02 saturations are calculated as $\mathrm{SpO} 2$ minus $\mathrm{SaO} 2$, and are reported as percentage point (pp) differences. SaO2=arterial O2 saturation; $\mathrm{SPO} 2=02$ saturation on oximetry.

\section{Figure 5-Association between SaO2 and SpO2 by ethnicity}

Figure A represents a generalized additive model (GAM), with the percentage point ( $p p$ ) difference in $\mathrm{O} 2$ saturations between $\mathrm{SpO} 2$ and $\mathrm{SaO} 2$ as the dependent variable, the smooth function of $\mathrm{SaO} 2$ as a covariate, and ethnicity as a nominal factor. Figure $B$ visualises the observed mean differences between $\mathrm{SpO} 2$ and $\mathrm{SaO} 2$ within intervals of $\mathrm{SaO} 2$, to validate the goodness of fit of the GAM model. Each interval had a width of $2 p p$, and points are plotted at the midpoint of the interval. Both plots are left-truncated at an $\mathrm{SaO} 2$ of $90 \%$, in order to better visualise the differences between groups. *Differences in $\mathrm{O} 2$ saturations are calculated as $\mathrm{SpO} 2$ minus $\mathrm{SaO} 2$, and are reported as percentage point ( $p p$ ) differences. $\mathrm{SaO2}=$ arterial $\mathrm{O} 2$ saturation; $\mathrm{SpO2}=\mathrm{O} 2$ saturation on oximetry.

\section{Figure 6-Association between SpO2 and the probability of normoxia (SaO2 $\geq 94.0 \%$ )}

In Figure A, points represent the probability of SaO2 $\geq 94.0 \%$ for SpO2 of 80-89\% (first point), and for each integer value of SpO2 from 90-100\%. Whiskers represent $95 \%$ confidence intervals. The red line is from a binary logistic regression model, with $\mathrm{SpO} 2$ as a continuous covariate. This model appeared to have suboptimal fit in for low values of SpO2, due to the greater inaccuracy of oximetry in this range. As such, a second model (broken line) was produced which only included the subset with $\mathrm{SpO}>90 \%$, which returned similar results in this range. In Figure $B$, the first binary logistic regression model was extended to include ethnicity as a factor, see Table 4 for further details; this figure is truncated at an $\mathrm{SpO} 2$ of $90 \%$, to more clearly highlight the difference between groups. SaO2=arterial $\mathrm{O} 2$ saturation; $\mathrm{SpO} 2=02$ saturation on oximetry. 
medRxiv preprint doi: https://doi.org/10.1101/2021.11.21.21266662; this version posted November 26, 2021. The copyright holder for this preprint (which was not certified by peer review) is the author/funder, who has granted medRxiv a license to display the preprint in perpetuity.

It is made available under a CC-BY-NC-ND 4.0 International license .

Supplementary Table 1 - Exclusions by ethnicity

\begin{tabular}{|c|c|c|c|c|c|}
\hline \multicolumn{2}{|c|}{02 Saturation } & \multicolumn{4}{|c|}{ Ethnicity } \\
\hline SpO2 & $\mathrm{SaO2*}$ & $\begin{array}{c}\text { White } \\
(\mathrm{N}=14300)\end{array}$ & $\begin{array}{c}\text { Asian } \\
(N=2049)\end{array}$ & $\begin{array}{c}\text { Black } \\
(N=723)\end{array}$ & $\begin{array}{c}\text { Other } \\
(N=547)\end{array}$ \\
\hline$\geq 80 \%$ & $\geq 79.5 \%$ & 13649 (95.4\%) & 1965 (95.9\%) & 674 (93.2\%) & 530 (96.9\%) \\
\hline$<80 \%$ & $\geq 79.5 \%$ & $92(0.6 \%)$ & $12(0.6 \%)$ & $6(0.8 \%)$ & $2(0.4 \%)$ \\
\hline$\geq 80 \%$ & $<79.5 \%$ & 501 (3.5\%) & 66 (3.2\%) & $41(5.7 \%)$ & $15(2.7 \%)$ \\
\hline$<80 \%$ & $<79.5 \%$ & $58(0.4 \%)$ & $6(0.3 \%)$ & $2(0.3 \%)$ & $0(0.0 \%)$ \\
\hline
\end{tabular}

Chi-square test: $p=0.077$. *A cut-off value of $79.5 \%$, rather than $80 \%$ was used for $A B G$, since values

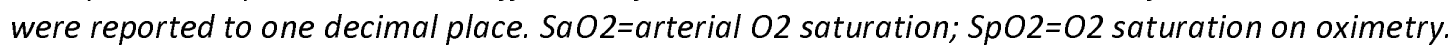




\section{References}

1. Pilcher J, Ploen L, McKinstry S, et al. A multicentre prospective observational study comparing arterial blood gas values to those obtained by pulse oximeters used in adult patients attending Australian and New Zealand hospitals. BMC Pulm Med 2020;20(1):7. doi: 10.1186/s12890-019-1007-3 [published Online First: 2020/01/11]

2. Aoyagi T, Miyasaka K. Pulse oximetry: its invention, contribution to medicine, and future tasks. Anesth Analg 2002;94(1 Suppl):S1-3. [published Online First: 2002/03/20]

3. Jubran A. Pulse oximetry. Crit Care 1999;3(2):R11-R17. doi: 10.1186/cc341 [published Online First: 2000/11/30]

4. Sinex JE. Pulse oximetry: principles and limitations. Am J Emerg Med 1999;17(1):5967. doi: 10.1016/s0735-6757(99)90019-0 [published Online First: 1999/02/03]

5. Chan ED, Chan MM, Chan MM. Pulse oximetry: understanding its basic principles facilitates appreciation of its limitations. Respir Med 2013;107(6):789-99. doi: 10.1016/j.rmed.2013.02.004 [published Online First: 2013/03/16]

6. Palmer E, Post B, Klapaukh R, et al. The Association between Supraphysiologic Arterial Oxygen Levels and Mortality in Critically Ill Patients. A Multicenter Observational Cohort Study. Am J Respir Crit Care Med 2019;200(11):1373-80. doi: 10.1164/rccm.201904-08490C [published Online First: 2019/09/13]

7. Food and Drug Administration. Pulse Oximeters - Premarket Notification Submissions: Guidance for Industry and Food and Drug Administration Staff. https://wwwfdagov/downloads/MedicalDevices/DeviceRegulationandGuidance/G uidanceDocuments/UCM081352pdf 2013;Accessed August 2021

8. Barker SJ, Tremper KK, Hyatt J. Effects of methemoglobinemia on pulse oximetry and mixed venous oximetry. Anesthesiology 1989;70(1):112-7. doi: 10.1097/00000542-198901000-00021 [published Online First: 1989/01/01]

9. Hampson NB. Pulse oximetry in severe carbon monoxide poisoning. Chest 1998;114(4):1036-41. doi: 10.1378/chest.114.4.1036 [published Online First: 1998/10/29]

10. Hinkelbein J, Koehler H, Genzwuerker HV, et al. Artificial acrylic finger nails may alter pulse oximetry measurement. Resuscitation 2007;74(1):75-82. doi: 10.1016/j.resuscitation.2006.11.018 [published Online First: 2007/03/14]

11. Pu LJ, Shen Y, Lu L, et al. Increased blood glycohemoglobin A1c levels lead to overestimation of arterial oxygen saturation by pulse oximetry in patients with type 2 diabetes. Cardiovasc Diabetol 2012;11:110. doi: 10.1186/1475-2840-11110 [published Online First: 2012/09/19]

12. Sjoding MW, Dickson RP, Iwashyna TJ, et al. Racial Bias in Pulse Oximetry Measurement. N Engl J Med 2020;383(25):2477-78. doi: 10.1056/NEJMc2029240 [published Online First: 2020/12/17]

13. Adler JN, Hughes LA, Vivilecchia R, et al. Effect of skin pigmentation on pulse oximetry accuracy in the emergency department. Acad Emerg Med 1998;5(10):965-70. doi: 10.1111/j.1553-2712.1998.tb02772.x [published Online First: 1998/12/23]

14. Foglia EE, Whyte RK, Chaudhary A, et al. The Effect of Skin Pigmentation on the Accuracy of Pulse Oximetry in Infants with Hypoxemia.J Pediatr 2017;182:37577 e2. doi: 10.1016/j.jpeds.2016.11.043 [published Online First: 2016/12/13] 
15. Emery JR. Skin pigmentation as an influence on the accuracy of pulse oximetry. $J$ Perinatol 1987;7(4):329-30. [published Online First: 1987/01/01]

16. Siemieniuk RAC, Chu DK, Kim LH, et al. Oxygen therapy for acutely ill medical patients: a clinical practice guideline. $B M J$ 2018;363:k4169. doi: 10.1136/bmj.k4169 [published Online First: 20181024]

17. Diao JA, Inker LA, Levey AS, et al. In Search of a Better Equation - Performance and Equity in Estimates of Kidney Function. N Engl J Med 2021;384(5):396-99. doi: 10.1056/NEJMp2028243 [published Online First: 2021/01/07]

18. Eneanya ND, Yang W, Reese PP. Reconsidering the Consequences of Using Race to Estimate Kidney Function. JAMA 2019;322(2):113-14. doi: 10.1001/jama.2019.5774 [published Online First: 2019/06/07]

19. Diao JA, Wu GJ, Taylor HA, et al. Clinical Implications of Removing Race From Estimates of Kidney Function. JAMA 2021;325(2):184-86. doi: 10.1001/jama.2020.22124 [published Online First: 2020/12/03]

20. Birmingham City Council. Population and Census. https://wwwbirminghamgovuk/info/20057/about birmingham/1294/population and census 2011;Accessed August 2021

21. O'Driscoll BR, Howard LS, Earis J, et al. BTS guideline for oxygen use in adults in healthcare and emergency settings. Thorax 2017;72(Suppl 1):ii1-ii90. doi: 10.1136/thoraxjnl-2016-209729

22. Bickler PE, Feiner JR, Severinghaus JW. Effects of skin pigmentation on pulse oximeter accuracy at low saturation. Anesthesiology 2005;102(4):715-9. doi: 10.1097/00000542-200504000-00004 [published Online First: 2005/03/26]

23. Sapey E, Gallier S, Mainey C, et al. Ethnicity and risk of death in patients hospitalised for COVID-19 infection in the UK: an observational cohort study in an urban catchment area. BMJ Open Respir Res 2020;7(1) doi: 10.1136/bmjresp-2020000644 [published Online First: 2020/09/03]

24. NHSx. Supporting care with remote monitoring. https://wwwnhsxnhsuk/covid-19response/technology-nhs/supporting-the-innovation-collaboratives-to-expandtheir-remote-monitoring-plans/2021;DOA 17th August 2021

25. Chapman ALN, Patel S, Horner C, et al. Updated good practice recommendations for outpatient parenteral antimicrobial therapy (OPAT) in adults and children in the UK. JAC Antimicrob Resist 2019;1(2):dlz026. doi: 10.1093/jacamr/dlz026

[published Online First: 2019/08/26] 


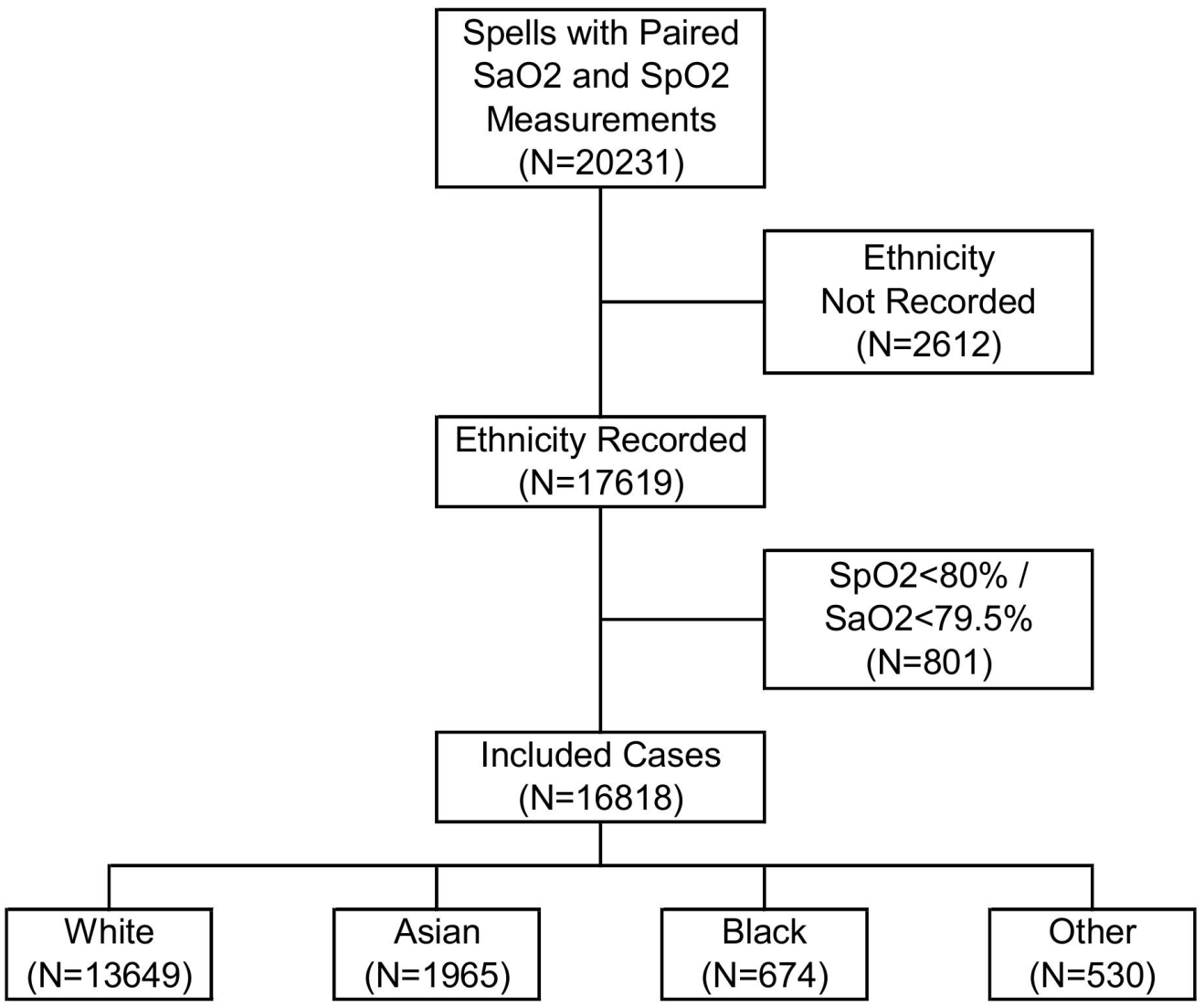


$A$



B





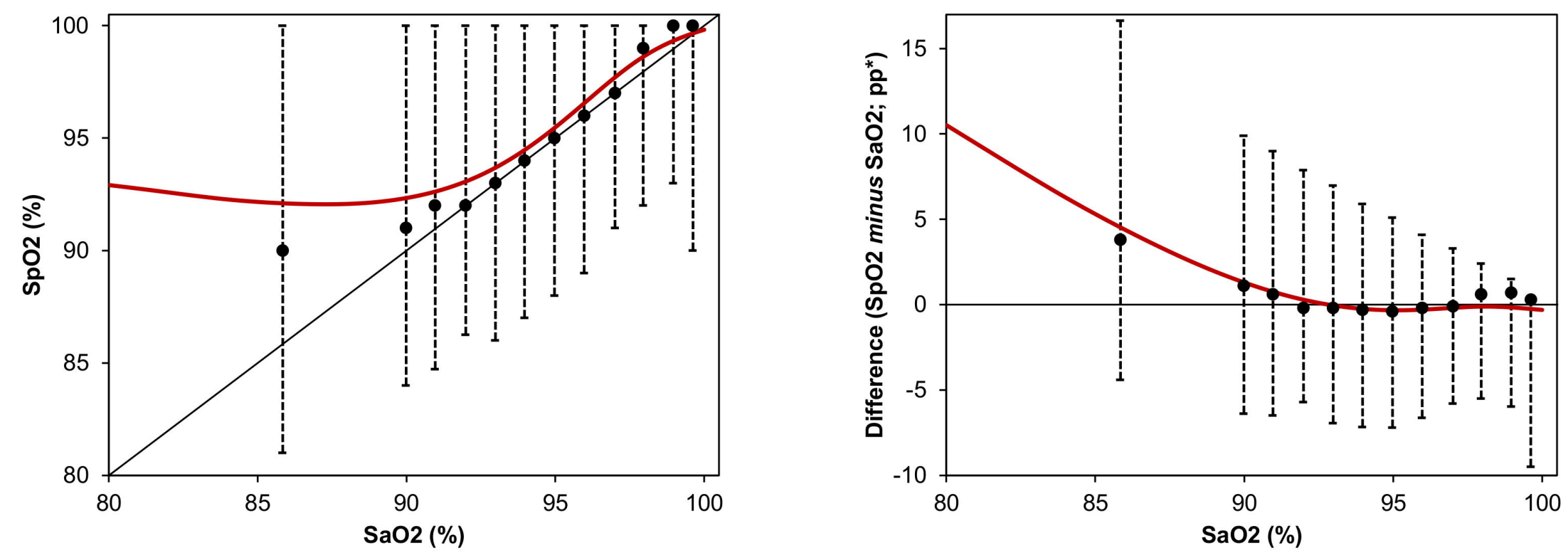






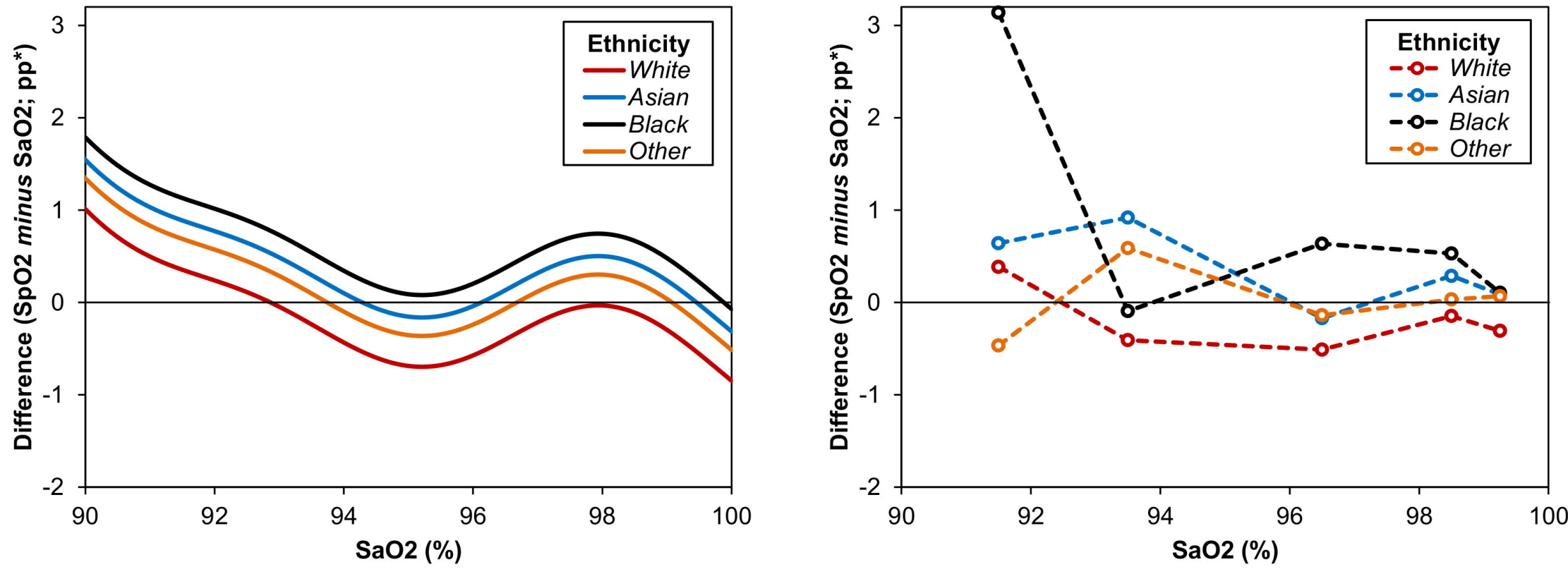

